\title{
THE DEVELOPMENT, MORPHOLOGY AND BUDDING OF THE ASCIDIAN DIAZONA
}

\author{
By N. J. Berrill \\ From the Plymouth Laboratory and McGill University, Montreal
}

(Text-figs. I-7)

Diazona is represented in European waters only by Diazona violacea Savigny. It is a compound ascidian forming massive colonies of spectacular size and appearance. In many ways it is the most interesting of all ascidians, for in its adult structure it straddles two commonly accepted orders and in itself is a strong argument against such a division; it is the only oviparous and smallegged compound ascidian, two features undoubtedly primitive; and its manner of budding is the simplest and probably is the basic type for the group as a whole. Only fragmentary descriptions of the morphology and reproduction exist, and a more or less complete account of the various stages of the life cycle may be of some value. The family Diazonidae includes, in addition to Diazona itself, the genera Tylobranchion of subantarctic regions, and Rhopalea of Mediterranean and northern waters. In its entirety Diazona appears to link with such divergent forms as Ciona on the one hand and Archidistoma on the other. The fact that Diazona is obtained by dredging in relatively swift offshore waters and lives poorly in an aquarium probably accounts for the existing unsatisfactory state of knowledge of most of its phases. Most of what is known concerns asexual reproduction; and attention has been given, at various times, primarily to the process of regeneration, rather than bud formation, for example by Della Valle (I884), Caullery (I9I4), Oka (I906) under the name Aphanobranchion, and by Salfi (1926).

The material of the present account was collected at various times in the Plymouth area from the Mewstone and Eddystone grounds.

\section{General Structure}

Diazona is usually found as large massive colonies exceeding in bulk all other known compound ascidians, both in aggregate and individual. All but the anterior ends of the zooids are embedded in a massive firm gelatinous matrix of tunicin. The individual zooid represents a combination of characters that is unique (Fig. I). It is merosomatous, that is, the body is divided into thorax and abdomen, the abdomen lying posterior to the thorax and joined to it by a relatively narrow oesophageal region. A slender vascular process descends from the posterior part of the abdomen far into the common test, branching and bearing a number of blind ampullary sacs. The vessels remain narrow, 
never becoming enlarged as in Clavelina (they contain an afferent and efferent vascular current). There are independent branchial and atrial siphons, and there is no tendency for individuals to become arranged in systems.

The thorax is relatively large, though seldom expanded in specimens in aquaria, and has sixty to seventy rows of stigmata in each branchial wall. Vascular papillae grow into the branchial cavity from the inner wall and bear
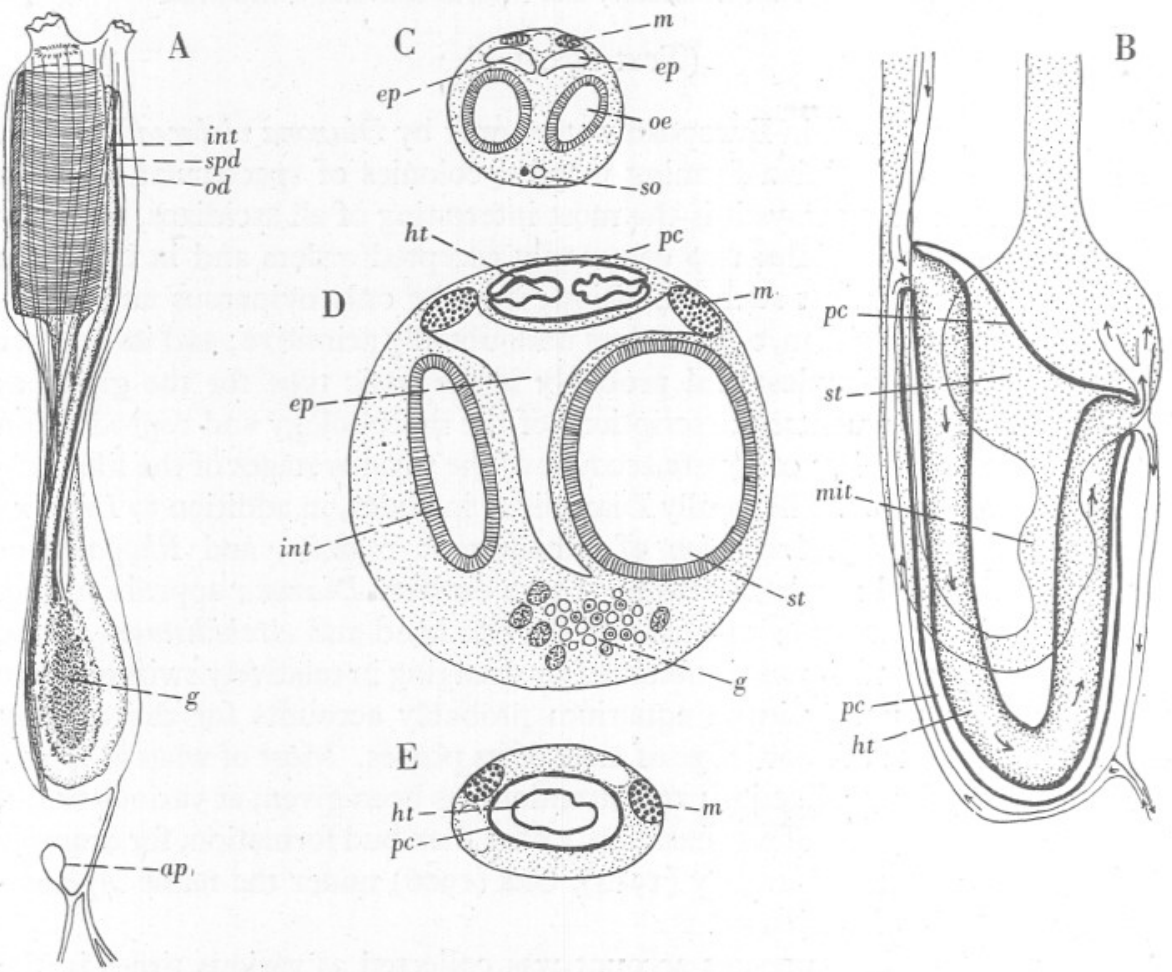

Fig. I. Morphology of Diazona violacea. A, complete mature zooid; B, heart, pericardium and digestive canal, reconstructed from serial sections; C, cross-section through oesophageal region, showing paired epicardial sacs; D, section at level of stomach, showing fused epicardia and heart; E, section posterior to digestive canal and epicardium, showing heart and terminal region of heart. $a p$, ampulla of stolonic vessel; $e p$, epicardium; $g$, gonad; $h t$, heart; int, intestine; $m$, muscle; mit, mid-intestine; od, oviduct; oe, oesophagus; $p c$, pericardium; so, sperm duct and oviduct; $s p d$, sperm duct; st, stomach.

the inner longitudinal vessels. Secondary papillae are absent, and the branchial $\mathrm{sac}$ is not otherwise complicated. Longitudinal muscles extend the length of the thorax and converge in the oesophageal region into a narrow band on the ventral side. Posteriorly in the abdomen the band is divided ventrally by the pericardium, and the two bundles become separately inserted at the base of the abdomen. White reflecting pigment cells congest the endostyle, peripharyngeal bands, and the dorsal lamina, making the combined system very 
conspicuous. The dorsal lamina is basically composed of a languet projecting into the branchial cavity corresponding to each of the sixty to seventy transverse blood vessels separating adjacent rows of stigmata.

The abdomen contains, in addition to the longitudinal muscles, the loop of the digestive canal, heart, epicardium, and the reproductive organs. The form of the digestive canal is obscure in whole specimens but is readily seen in regenerating forms and from serial sections. The long narrow oesophagus expands into a globular stomach. Posteriorly the stomach constricts and then the canal expands again to form the mid-intestine, which opens into the base of the loop, the intestine proper or rectum. This last ascends the abdomen and thorax to open close to the atrial siphon.

The pericardium and heart occupy the lower half of the abdomen on the ventral side. The pericardium is a simple sac, blind at the base, extending higher on the left than the right side, and wider laterally than dorso-ventrally. The heart is a deep invagination of the pericardial wall extending the whole length of the lateral margin, from the high left shoulder of the pericardium to its base and along the right side to the region of the stomach, forming a deep $\mathrm{V}$-shaped tube. In a functional sense the invagination is closed to form a deep tube of contractile cardiac tissue. Morphologically it remains continuous with the pericardium and the cardiac lips merely approximate to form the so-called 'raphe' of the heart. The vessels connected with the two ends of the heart are similar to those of other merosomatous forms and of Ciona. Entering the high ventral end are two vessels, one of which extends through the oesophageal region and becomes the sub-endostylar vessel. The other passes posteriorly and enters the narrow stolonic vessel together with a similar vessel from the dorsal end of the heart. The two channels thus formed are separated by a mesenchymatous septum. The dorsal end of the heart is also supplied with vessels from the stomach region and the blood sinuses of the body as a whole, of blastocoelic character.

The epicardia for the most part are fused to form a median chamber, as in all other merosomatous ascidians except Euherdmania and the Didemnidae. They end blindly just beneath the posterior wall of the branchial sac, one on each side, and extend as separate tubes through the oesophageal region, lying between the digestive canal and muscle band. Near the stomach fusion occurs to form a single large cavity apposed ventrally to the pericardium, with a lateral horn reaching the muscle band on each side, and a median dorsal extension between the descending and ascending limbs of the digestive canal. Posteriorly it ends blindly at a level intermediate between the end of the pericardium and the bend of the gut.

The gonad is a large hermaphrodite gland consisting of a centrally situated ovary with numerous and relatively small eggs, with numerous peripheral testicular follicles, the whole mass lying across the loop of the digestive canal posterior to the oesophagus, on the left side. Both sperm duct and oviduct are 
fairly straight and accompany the rectum to open near the anus just below the atrial siphon. This proximity, together with the small size of the eggs, assures a condition of oviparity.

\section{Sexual Reproduction and Development}

Sexual maturity is reached in July and lasts into September. Eggs are liberated in fair number and develop outside of the colony. They are very similar to those of the Ascidiidae, both in size (0.1 mm.), and in the character and number of the outer and inner follicle cells (Fig. 2A). The outer cells are typical, neither exhibiting the flattening out over the chorion as in viviparous forms, nor specialized as 'floats' to the extent found in Ciona intestinalis, Corella parallelogramma and Ascidiella aspersa.
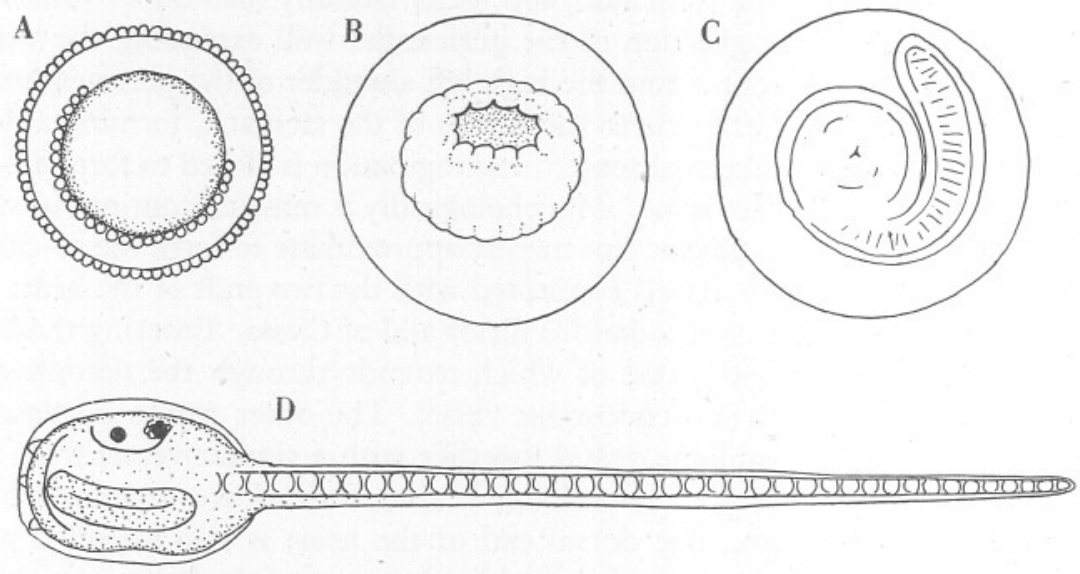

Fig. 2. Diazona violacea, development of tadpole. A, egg; B, gastrula; C, embryo; D, tadpole.

At $16^{\circ} \mathrm{C}$., gastrulation occurs after about $5 \mathrm{hr}$., and is enbolic as in most ascidian eggs of this size (Fig. 2B). The transparency of the egg is indicative of a relatively small amount of yolk. The tadpole (Fig. 2D) hatches by digestion of the chorion after $26-27 \mathrm{hr}$. at the above temperature. Tadpoles at first are positively heliotropic, and the free-swimming period is normally from 20 to $24 \mathrm{hr}$. In general, the tadpole larva is much like that of the above three forms, both in size and appearance. The endostyle is more or less horizontal at this stage. The sensory vesicle contains the usual single-celled otolith and 3-lens ocellus. The three adhesive papillae are simple. There are about forty notochord cells in the tail, and the cuticular tail fin is virtually absent.

The process of metamorphosis is prolonged (Fig. 3). After fixation by the adhesive papillae, the tail absorbs and the anterior end of the trunk grows out as the preoral lobe, as in Ciona. Rotation occurs, and after Io or II days at $16^{\circ} \mathrm{C}$., the siphons are contractile and the heart is beating. The characteristic 
rythmical reversal of heart beat is exhibited from the beginning. The cilia of the gill slits beat actively about I6 days after fixation. During this period the preoral lobe grows as the stalk attaching the young Diazonid individual to the substratum. Finally it is a vertical stalk as long as the trunk proper, divided basally into two or three wide anchoring lobes. As in Ciona, Corella and

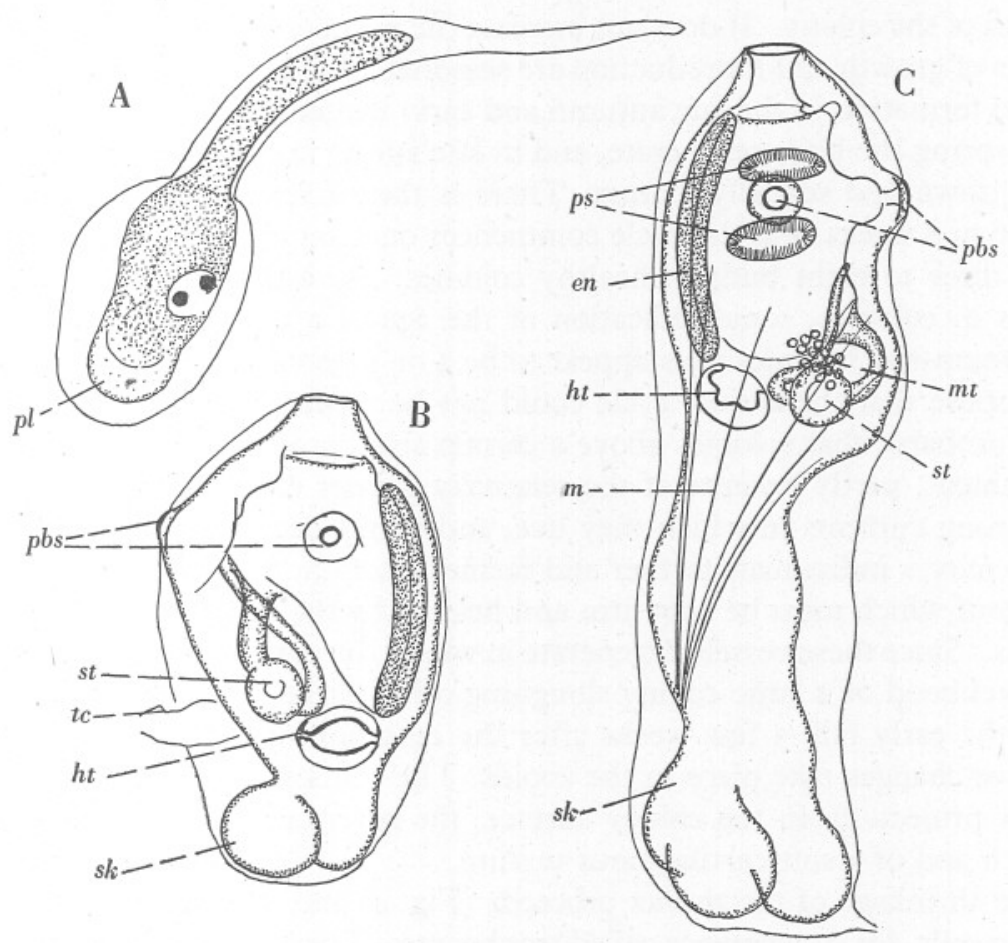

Fig. 3. Diazona violacea, post-larval development. A, metamorphosing tadpole with preoral lobe. B, stage 9 days later with active heart and siphons but no cilia; C, stage 5 days later (at $\mathrm{I} 6^{\circ} \mathrm{C}$.) fully active, with paired peribranchial siphons. en, endostyle; $h t$, heart; $m$, muscle; $m t$, resorbed muscle cells of tail; $p l$, preoral lobe; $p b s$, peribranchial siphons; $p s$, protostigmata; $s k$, stalk; st, stomach; $t c$, tunic remnant of tail.

Ascidia, at this stage, there is a single branchial siphon and in place of a mediandorsal atrial siphon there are a pair of very widely separated peribranchial siphons, extending laterally from the body wall. Each connects with a peribranchial sac associated with two large protostigmata. The digestive canal lies more or less horizontally immediately beneath the branchial sac, as in Ciona, and at this stage shows no inclination to descend into the stalk. The heart is simple and lies directly between the base of the endostyle and the bend of the intestine. A group of longitudinal muscles extends from the trunk into the 
stalk, and when contracting causes the ascidian to bend in an arc about the junction of stalk and trunk. An avoidance reaction is strongly suggested.

This is the latest stage to which the oozooid has been raised, and there is a remarkable resemblance to the equivalent stage of Ciona.

\section{ASEXUAL REPRODUCTION}

Asexual reproduction or budding concerns entirely the establishment and growth of the colony. It does not increase the number of colonies. The various phases of growth and reproduction are seasonal. A colony undergoes a process of bud formation in the late autumn and early winter. During late winter and early spring the buds regenerate, and in late spring and early summer become fully grown and sexually mature. There is then a sexual breeding season of from 6 to 8 weeks, and the cycle commences once more. Each zooid produces from three to eight buds in healthy colonies. By estimating the number of zooids in colonies, some indication of the age of a colony can be obtained. Maximum-size colonies thus appear to be 4 or 5 years old. There is no reason to suppose that the annual cycle could not be repeated indefinitely, but it is most probable that colonies above a certain size become dislodged from their attachment, partly because of the relatively greater exposure to the action of the strong currents in which they live, and partly because increase in colony size removes individuals farther and farther from the base of attachment, the matrix of which must be kept firm and healthy by the activity of their stolonic vessels. Since these vessels degenerate in winter during the process of budding, the likelihood of a large colony sloughing off must be great.

In the early fall, a few weeks after the cessation of sexual breeding, progressive changes take place in the zooids. The thorax of each shrinks, and no longer projects from the colony surface, the latter becoming finally perfectly smooth and of a soft cartilaginous texture.

The shrinkage of the thorax proceeds (Fig. 4) and is due to the activity of certain cells, for convenience called trophocytes. These cells, of obscure origin, derived probably from blood cells, appear throughout the thorax and grow in size as they accumulate within themselves a pseudovitellus or protein reserve. They probably arise in the same way as, and are homologous with, the cells described by Spek (1927) from living vitally stained tissues of Clavelina. A comparable histological study of resorption in Diazona along such lines would be of interest. Their appearance or growth occurs simultaneously with a shrinkage or autolysis of the differentiated thoracic structure, and is followed, as in Clavelina and many other forms, by a migration of the trophocytes towards the posterior end of the zooid. The cells are too large to enter the narrow stolonic vessels (which in Clavelina are large and become congested), and it is the abdomen and oesophageal region that becomes distended with them. The thorax survives for a while as a faint ghost of itself, but finally disappears entirely. The trophocytes form a nutritive reserve, but they 
neither take an active part in the formation of buds nor contribute to new structures apart from the maintenance of the nutritive medium in which such structures develop. Bud-formation is essentially a process of epidermal strobilation or constriction. As the trophocytes withdraw from the anterior regions, transverse constrictions develop that cut deep into the internal tissues. The narrow oesophageal 'neck' is involved to a varying extent, the abdomen from the posterior end to just anterior to the stomach not at all. The constrictions for the most part occur in the intermediate zone anterior to the stomach. As far as can be determined the constrictions appear and develop simultaneously, finally
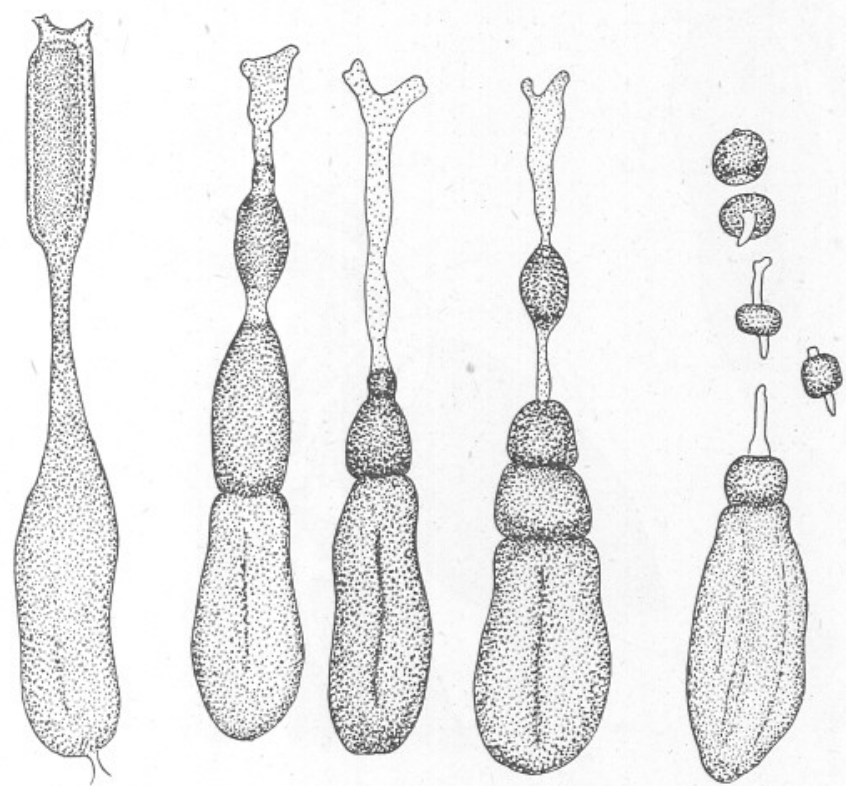

Fig. 4. Diazona violacea. Five zooids illustrating stages in resorption, posterior congestion by trophocytes, and strobilation.

isolating masses more or less at the same time, with the exception of the most posterior constriction. This last constriction may commence later than the more anterior, but it is also possible that the belated separation of the bud is due to the greater growth of the process. Anyhow, it is a typical condition for four or five more or less spherical masses to be isolated in series immediately anterior to, and in line with, the posterior part of the abdomen, with the proximal bud regenerating from the anterior end and still in process of constriction posteriorly. Finally, this bud too is isolated and the large abdominal remnant regenerates anteriorly. Frequently a mass may undergo isolation in the anterior oesophageal region, the region immediately posterior to it evacuated, and the posterior strobilating part connected with it by 'ghost' tissue. It raises the question of the relative roles of epidermis and internal tissues. 
Two phenomena require elucidation - the fact of constriction itself, and the virtual spherical shape of the constricted mass. Sectioned material confirms the conclusion derived from direct observation on intact constricting zooids, that there is necessarily a real growth of epidermis in order to produce the deep folds (Figs. 5, 6). In the narrow band of the constriction itself the epidermal cells are unusually large and show every appearance of extensive growth, pressing against, and in effect dividing, the trophocyte mass, actually cutting through the longitudinal muscle, epicardium, and limbs of the digestive canal.

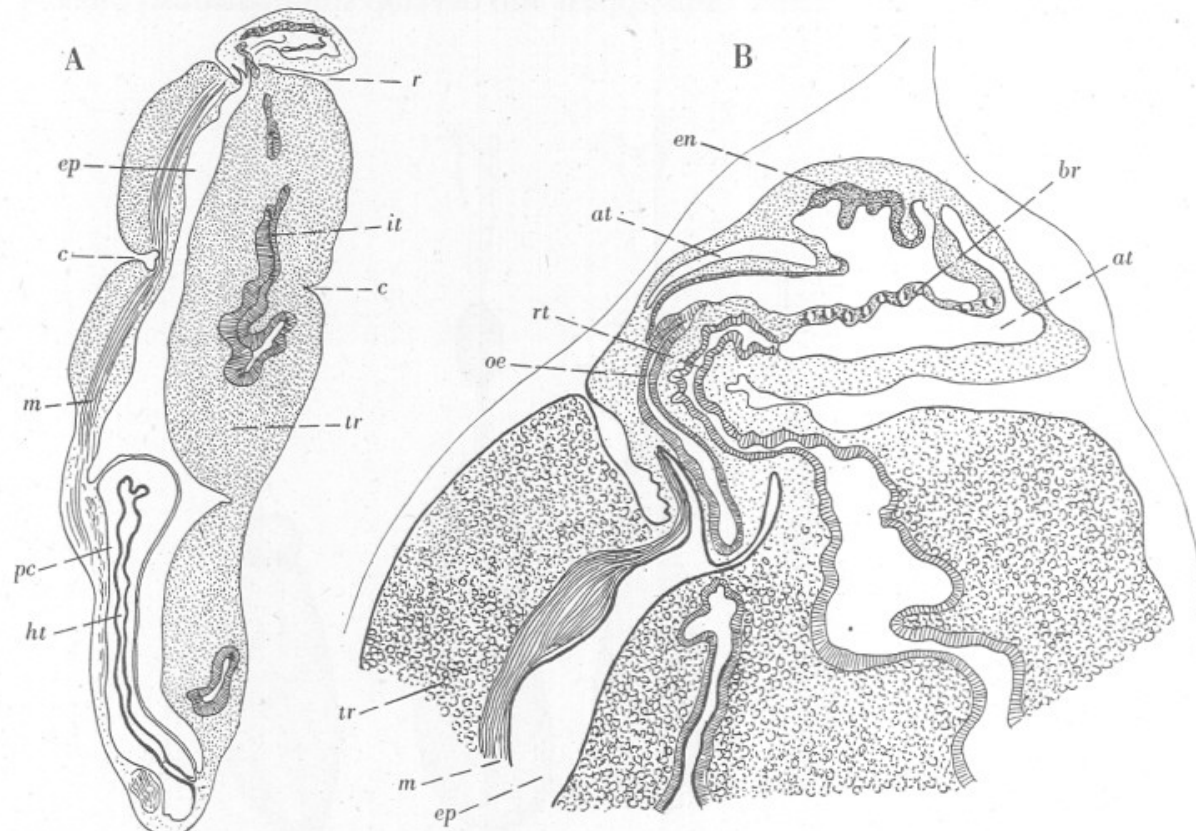

Fig. 5. Diazona violacea. Longitudinal sections through strobilating and regenerating abdomen, showing anterior regeneration of thorax from horns of epicardia, a midabdominal constriction, and the persistence of the heart and other structures. ct, atrial cavities; $b r$, branchial wall; $c$, constriction; $e n$, endostyle; ep, epicardium; $h t$, heart; $i t$, intestine; $m$, longitudinal muscle; oe, new oesophagus; $p c$, pericardium; $r$, rectum; $r t$, new rectum; $t r$, trophocytes.

The epidermal tissue grades gradually from the actively growing tissue at the cutting surface back to the inactive tissue at the original surface of the zooid, indicating a slow recovery of normal cell size and appearance with the cessation of growth. All of the internal tissues are purely passive, playing no part in the process of constriction itself.

When constriction nears completion and later until regenerative processes modify the initial shape, a bud is practically spherical. This appears to be due to a freedom of movement of the large trophocytes, so that the shape of the whole contained mass of them conforms to the action of surface forces, as would a mass of small greased balls within a contracting envelope. 
Salfi (1926) discusses the process of bud production in Diazona in terms of Child's 'physiological isolation', but whatever this may be it does not seem to apply here. Resorption of the thorax is a common phenomenon among compound ascidians and is generally followed by its regeneration from the oesophageal region or from the abdomen. In Diazona this process is combined with that of strobilation of the anterior abdominal and oesophageal region. The posterior abdominal region regenerates anteriorly in the usual way. Strobilation itself is something clearly distinct from 'physiological

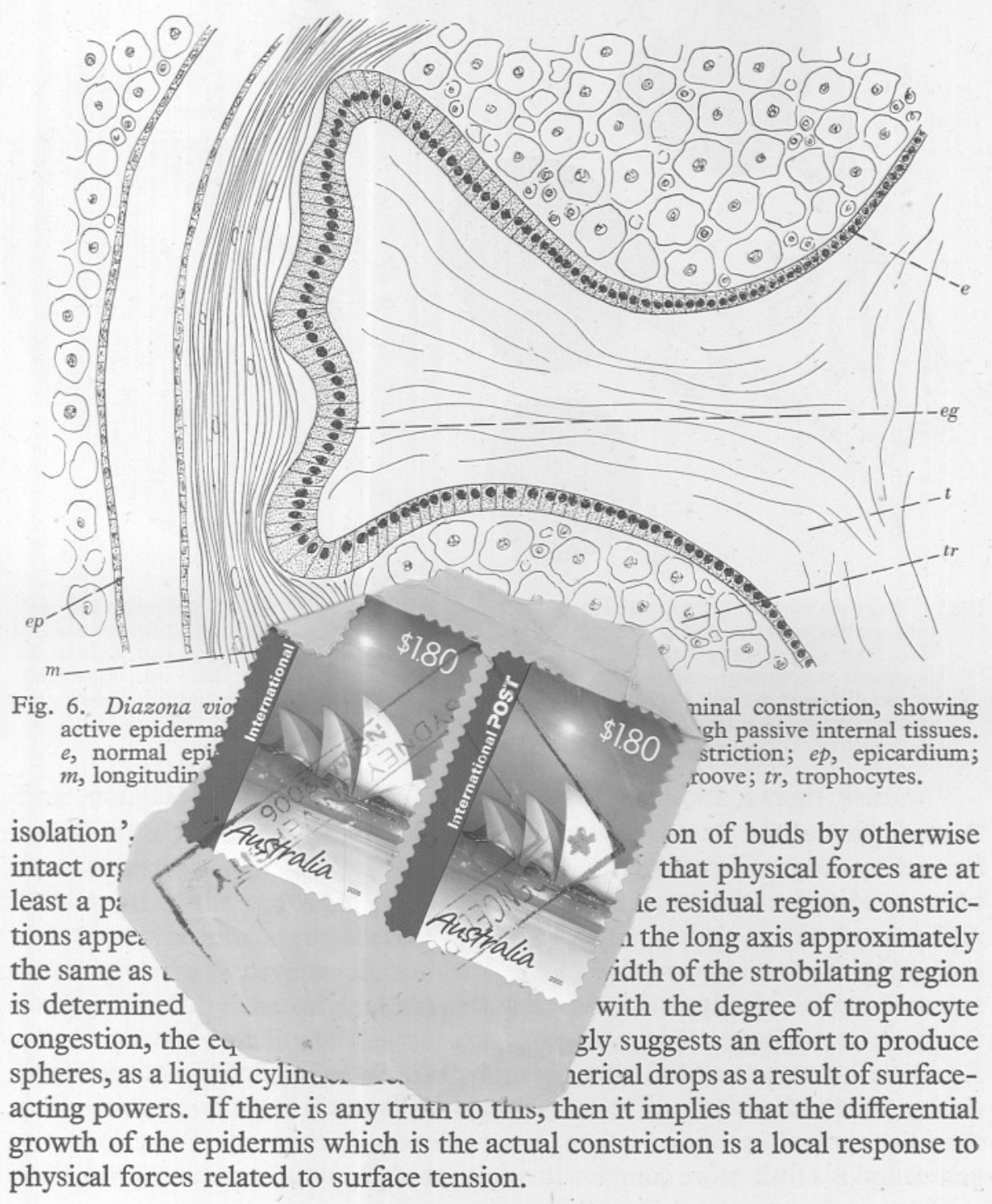


The phenomena of reconstitution have been studied by Salfi in some detail. His observations are more or less confirmed, namely, that the fragments of the epicardium, longitudinal muscles, and descending and ascending limbs of the digestive canal survive, and that regeneration at the anterior and posterior surfaces is due almost entirely to epidermal growth forming the new epidermis, and the epicardium the internal structures (Fig. 7).

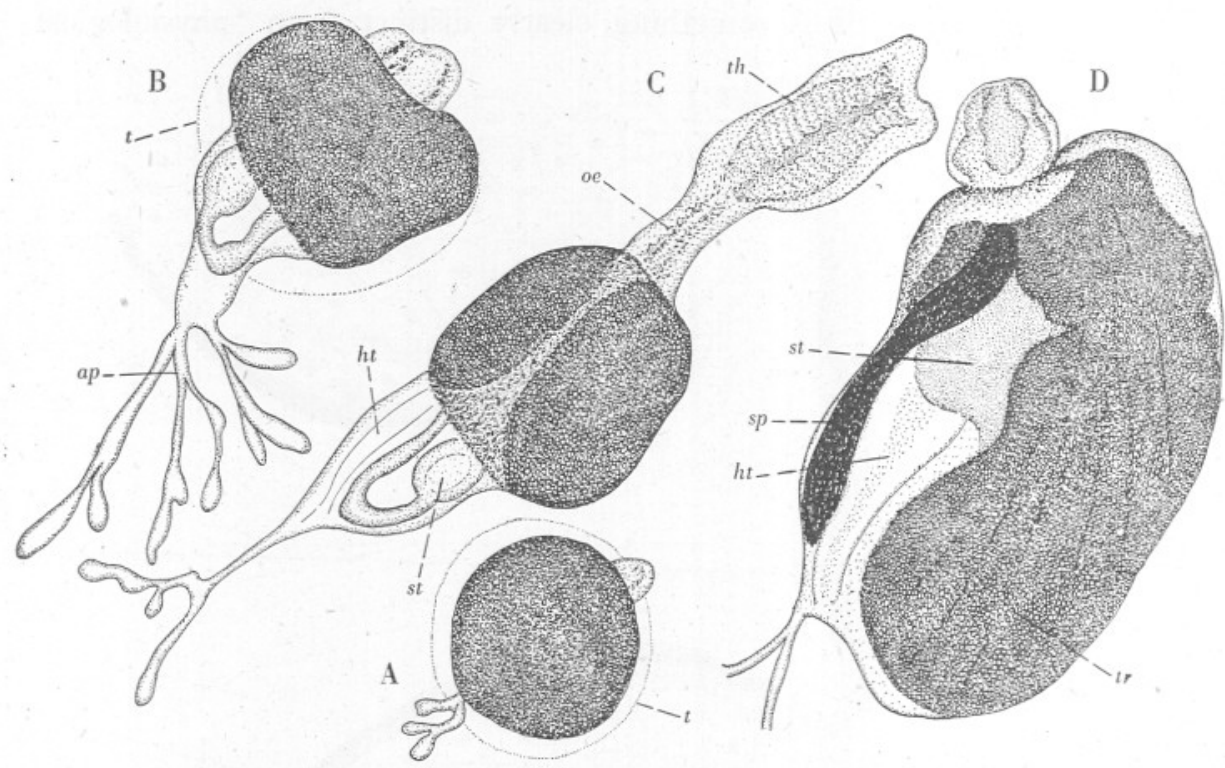

Fig. 7. Diazona violacea. Isolated buds in process of regeneration. A, bud still spherical and just starting anterior and posterior regeneration (dotted line indicates zone of new tunic); $\mathrm{B}, \mathrm{C}$, later stages of regeneration; D, anterior regeneration from large posterior abdominal fragment containing old heart, stomach, distended sperm duct, etc. $a p$, ampullary stolonic vessels of test; $h t$, heart; oe, oesophagus; $s t$, stomach; $s p$, sperm duct; $t$, new test substance; $t h$, new thorax; $t r$, trophocytes.

The new thorax, including the branchial sac, atrial sacs, ganglion, and thoracic part of the intestine, but excluding the epidermis, arises from tissue formed by the proliferating anterior end of the epicardium. The new intestine becomes joined to the remnant of the old. There is some indication of cellular replacement within the old sections of the digestive tube even though there is continuity in gross appearance. The regenerating branchial sac develops about seventeen rows of stigmata, the number varying somewhat with the size of the bud, but always a number far less than that typical of mature adults. Additional rows are added after the reconstituted zooid becomes functional, during renewed growth. The early stages of thoracic morphogenesis, other than the general epicardial origin, has not been determined. Posteriorly regeneration is a little more complex in origins though not in structures produced. 
The epidermis grows out and branches terminally to form clusters of stolonic vessels. As far as can be determined from somewhat limited material, the two posterior ends of the digestive canal fragments unite and the loop grows posteriorly keeping pace with the epidermal outgrowth, and at an early stage shows differentiation into stomach, post-stomach, and mid-intestine regions. The new pericardium and heart appear to develop from the posterior extremity of the epicardium, as in Aplidium (Brien, 1925). Unlike the majority of ascidian buds, therefore, reconstitution of the new zooid is fundamentally a typical regeneration process from anterior and posterior surfaces, rather than either reorganization or a virtual complete development.

With continued growth of the structures thus established, the opaque mass of the original bud gradually becomes progressively transparent and eventually forms an elongated oesophageal region of the reconstituted individual. This is complete in early spring, and growth to sexual maturity occupies a succeeding 2 or 3 months.

\section{REFERENCES}

BRIEN, P., I925. Contribution à l'étude de la blastogénèse des Tuniciers. Bourgeonnement chez Aplidium zostericola (Giard). Arch. Biol., T. xxxv, pp. I55-205.

Caullery, M., I9I4. Sur Diazona geayi n.sp., Ascidie nouvelle de la Guyane, et sur la régénération et le bourgeonnement de Diazona. Bull. Soc. Zool. France, T. XxxIX, pp. 204-II.

Della Valle, A., I884. Sul ringiovanimento delle colonie di Diazona violacea Sav. Rend. Accad. Sc. Fis. Mat. Napoli, Vol. xxiII, pp. 23-6.

Garstang, W., I89I. Report on the Tunicata of Plymouth. Part I. Clavelinidae, Perophoridae, Diazonidae. Fourn. Mar. Biol. Assoc., Vol. II, pp. 47-67.

OкA, A., 1906. Aphanibranchion, eine neue Synascidiengattung aus Japan. Annot. zool. Fap., Vol. v, pp. 253-65.

SAlfi, M., I925. Sul ringiovanimento della Rhopaloea neapolitana Phil. Boll. Soc. Nat. Napoli, Vol. xxxvir, pp. 85-9.

SALFI, M., I926. Richerche sul ringiovanimento e sulla blastogenesi in Diazona violacea Sav. Pubbl. Staz. Zool. Napoli, Vol. viI, pp. 335-66.

SPEK, J., I927. Über die Winterknospenentwicklung, Regeneration und Reduktion bei Clavelina lepadiformis und die Bedeutung besonderer "Omnipotenter" Zellelemente für diese Vorgänge. Arch. Entw. Mech., Bd. CXI, pp. II9-72. 